\title{
ESCOLA PÚBLICA E DEMOCRACIA NO BRASIL: ALGUNS APONTAMENTOS
}

\author{
SOME NOTES ON PUBLIC SCHOOLS AND \\ DEMOCRACY IN BRAZIL
}

\section{Eduardo Donizeti Girotto*}

\begin{abstract}
RESUMO
A escola pública ganha visibilidade na ordem atual das coisas. Basta um olhar um pouco mais atento para os diversos meios de comunicação para que esta constatação se torne efetiva. Ao mesmo tempo, porém, é possível perceber que tal visibilidade joga luz muito mais sobre os problemas do que sobre os avanços da mesma. Ela é acusada, por todos os lados, por sua incapacidade de ensinar, educar, controlar, disciplinar - enfim, de não cumprir todos os anseios projetados sobre ela pela sociedade. Mas é preciso ir além dessa constatação para se compreender os processos e fenômenos relacionados que envolvem as transformações pelas quais vem passando a escola pública nas últimas décadas, bem como analisar de forma atenta, séria e crítica as relações intrínsecas existentes entre as problemáticas que envolvem, ao mesmo tempo, a escola e a sociedade. Nesse sentido, a partir de leituras e pesquisas desenvolvidas em duas escolas públicas localizadas na região metropolitana de São Paulo entre os anos de 2009-2011, buscaremos discutir a relação entre escola pública e a democracia no Brasil, partindo do pressuposto de que ambas são fenômenos recentes e em plena construção. Essa afirmação se faz necessária para não transpormos para a realidade brasileira determinadas interpretações realizadas para explicar as problemáticas das escolas públicas em outros países. Por mais que existam traços comuns, há mais elementos de diferenciação do que de identidade. Portanto, compreender a escola pública brasileira passa, necessariamente, por uma compreensão das questões centrais do desenvolvimento do Estado brasileiro, das suas contradições, estratégias e crises.
\end{abstract}

Palavras-chave: Democracia. Patrimonialismo. Neoliberalismo. Sociedade Civil. Educação.

\begin{abstract}
Public schools have gained visibility in recent times. A closer look to the various media demonstrates that this is a fact. At the same time, however, it is possible to observe that such visibility sheds light more on problems than on the progress that public schools achieved. Public schools have been criticized by their inability to teach, educate, control and discipline, that is, public schools have been accused of not fulfilling the roles expected by society. It is necessary to go beyond this observation to understand the processes and related phenomena involving the transformations through which publics have gone through in recent decades, as
\end{abstract}

\footnotetext{
* Doutorando em Geografia Humana, USP. Professor Assistente do Colegiado de Geografia da Universidade Estadual do Oeste do Paraná.
} 
well as analyze with a serious and critical perspective the relations between the intrinsic problems that involve schools and society at the same time. In this sense, based on readings and research developed in two public schools located in the metropolitan region of São Paulo between the years 2009-2011 this paper seeks to discuss the relationship between public schools and democracy in Brazil, assuming that both are recent phenomena in construction. This statement is necessary in order not to bring to Brazilian reality certain interpretations made to explain the problems of public schools in other countries. As much as there are common traits there are many more elements of differentiation than of identification. Therefore, understanding Brazilian public schools is done by understanding the central issues of development of the Brazilian state, its contradictions, strategies and crises.

Keywords: Democracy. Patrimonialism. Neoliberalism. Civil Society. Education.

\section{Introdução: a escola pública em um Estado por se fazer}

O Estado brasileiro, enquanto organização autônoma e independente juridicamente, é uma conquista bastante recente. $\mathrm{O}$ processo violento de ocupação, exploração e destruição do território e das relações sociais aqui existentes, iniciado com os portugueses ainda no século XVI, estendeu-se, de diferentes formas, por mais de 300 anos e ainda deixa marcas na dinâmica da sociedade brasileira (FAORO, 2001). Além do endividamento econômico, das relações de dependência política, tal processo trouxe elementos e valores sociopolíticos que definem as práticas e ações da população brasileira. $\mathrm{O}$ chamado "jeitinho brasileiro", que se expressa pela reprodução dos privilégios em detrimento dos direitos fundamentais, é uma dessas marcas deixadas pelo processo de construção socioespacial do Brasil.

Em seu livro Raízes do Brasil, Sérgio Buarque de Holanda analisa uma das implicações desse processo no desenvolvimento das ações e do sentido do Estado brasileiro. Para o autor, uma das questões fundamentais que permeiam as relações sociais e políticas no Brasil diz respeito à falta de distinção entre a esfera da família e a esfera do Estado, entre o privado e o público. Em certa medida, em nosso país, o Estado é considerado uma continuidade, uma ampliação da esfera familiar, o que justifica a ocorrência, no interior de sua formação, de práticas pautadas por interesses individuais. Como aponta o autor,

No Brasil, pode-se dizer que só excepcionalmente tivemos um sistema administrativo e um corpo de funcionários puramente dedicados a interesses objetivos e fundados neste interesse. Ao contrário, é possível acompanhar, ao longo de nossa história, o predomínio constante das vontades particulares que encontram seu ambiente próprio em círculos fechados e pouco acessíveis a uma ordenação impessoal. Dentre esses círculos, foi sem dúvida o da família aquele que se exprimiu com mais força e desenvoltura em nossa sociedade. (HOLANDA, 2001, p. 146).

Em certa medida, essa confusão entre o que se refere à esfera do Estado e o que se refere à esfera da família está diretamente relacionada aos fundamentos do processo de colonização ocorrido em nosso país. Como terra do rei durante muito tempo, habitada por uma população retirada à força de sua terra natal e aqui colocada na condição de escravo, nunca houve no Brasil um processo de diferenciação entre aquilo que diz respeito à esfera pública, os assuntos comuns e de responsabilidade coletiva, e a esfera privada, dos domínios particulares. Ao contrário, a distinção entre público e privado foi sempre resultado da vontade do rei que, no final das contas, era o efetivo dono não apenas das terras, mas das vidas dos que nelas habitavam.

Da mesma forma, esta noção se assenta, juridicamente, na forma como o sistema de capitanias hereditárias estava organizado. Só com o consentimento do rei as terras poderiam ser entregues aos capitães donatários que tinham por obrigação fazê-las produzir, ao mesmo tempo que aumentavam a possibilidade de ocupação do território ao repassarem partes destas terras (sesmarias) a outros homens de sua confiança. Porém, juridicamente, apesar des- 
sa aparência de que as terras se encontravam dispersas nos domínios de diferentes senhores, eram todas domínios do rei e, a qualquer momento, ao mesmo poderiam retornar.

Nesse sentido, o Estado brasileiro se configura enquanto Estado patrimonial no qual a própria gestão pública se apresenta como interesse de ordem particular. Como aponto o autor,

as funções, os empregos, os benefícios que deles aufere relacionam-se a direitos pessoais do funcionário e não a interesses objetivos, como sucede no verdadeiro Estado burocrático, em que prevalecem a especialização das funções e o esforço para se assegurarem garantias jurídicas aos cidadãos (HOLANDA, 2001, p. 146).

Com esta configuração jurídica feudal e com a implantação do trabalho escravo, forma-se no Brasil, desde o princípio, uma confusão entre a esfera pública e a privada, sendo o direito substituído pela força da coerção e da violência. Como não há uma esfera pública - um espaço dominado pelas leis estabelecidas de forma comum e que se tornam claras para todos aqueles que a elas estão submetidas -, cria-se o domínio da força e da violência. Não se trata apenas das práticas coronelistas que persistem ainda em muitas partes do país. Trata-se, principalmente, da substituição e da confusão entre as noções de direito e privilégio. O homem cordial, apontado por Sérgio Buarque de Holanda, é resultado desse processo. Não se trata do cordial como elemento pacificador ou coisa que o valha, mas da paixão e da violência, do homem que substitui a razão pela pulsão na tentativa de resolver questões que, pela inexistência ou não do reconhecimento da lei, não podem ser resolvidas de outra forma. Esse homem cordial não reconhece o outro enquanto sujeito do processo, pois para ele a sua vontade, o seu desejo, a sua pulsão passam a ser os determinantes em todo o processo.

Tais conceitos, desenvolvidos por Sérgio Buarque de Holanda, tornam-se mais compreensíveis se levarmos em consideração o momento no qual o autor está produzindo a sua obra. Sérgio Buarque faz parte de uma geração de pensadores (Celso Furtado, Caio Prado Jr., Anísio Teixeira, Fernando Azevedo) que decidiram produzir reflexões importantes sobre as condições sociais, políticas e econômicas de nos- so país. Em suas obras, tais autores, cada qual a sua maneira, fazem uma leitura de nosso processo de formação enquanto povo, ressaltando aspectos específicos. Nesse sentido, por mais que os conceitos do autor pareçam bastante generalizantes, a leitura a ser feita diz respeito à busca de traços gerais de nossa personalidade enquanto povo daquilo que, pelo menos de forma parcial, influencia em nossas práticas cotidianas e que, muitas vezes sem perceber, reproduzimos sem nenhum tipo de questionamento. A compreensão desses traços gerais (das nossas raízes, como sugere o título do livro de Holanda) se faz necessária no sentido de entendermos que, ao lidar com a formação de cidadãos a partir da educação, temos uma tarefa que se configura mais complexa, de acordo com a realidade e as condições objetivas e subjetivas existentes em nosso país.

\section{Educação pública e gestão democrática no Brasil: tensões e possibilidades}

A tradição escolar brasileira é herdeira de duas grandes correntes autoritárias de organização da vida política e social: de um lado, muitos de seus fundamentos podem ser encontrados na estrutura educacional dos primeiros séculos de ocupação territorial portuguesa decorrente da atuação dos jesuítas, em seu projeto catequético ultramarino. De outro lado, a educação brasileira é resultante do projeto dos governos militares de expansão do acesso à escolarização básica como forma de controle social, posto em prática principalmente a partir da década de 1970 e que tem na lei federal no 5.692/71 sua principal legislação norteadora (SAVIANI, 2008).

A educação jesuítica tinha uma dupla função durante o Brasil colonial. De um lado, configurou-se como uma importante estratégia de controle, conhecimento, exploração e expansão territorial. A partir do discurso da necessidade de se catequizar os índios e apresentar-lhes "a verdadeira fé", as missões jesuíticas foram fundamentais para que o processo de interiorização do território brasileiro, principalmente nas regiões Norte e Sul, pudesse ocorrer, garantindo assim a efetiva ocupação das terras localizadas além do Tratado de Tordesilhas e que passaram para o domínio português a partir da assinatura do Tratado de Madri. Por outro lado, a educação jesuítica contribuiu para a formação dos 
filhos de alguns nobres portugueses/brasileiros que puderam assim se preparar para a continuidade dos estudos na Europa.

Essa segunda função da educação jesuíta no Brasil colônia ajudou no desenvolvimento da concepção de educação enquanto um privilégio e não um direito. Restrita apenas às elites, a educação jesuítica reproduzia os lugares sociais em uma estrutura de classes extremamente desigual. Controle e reprodução, os principais elementos dessa educação, permanecem ainda muito presentes na organização da educação brasileira atual.

Já a escola autoritária pensada e articulada pelo regime militar (1964-1985) em parceria com a burguesia nacional e internacional tinha, em discurso, o objetivo de sanar o problema da demanda de mão de obra qualificada para as multinacionais que acabavam de se implantar no Brasil. Era necessária formação técnica para que o chamado "milagre econômico" da década de 1970 pudesse ocorrer. A escola autoritária cumpria, portanto, esse papel e o fazia a partir da reprodução de um modelo de ensino pautado na nítida divisão entre o saber acadêmico e o saber técnico. A escola autoritária se dividia em duas: de um lado, a que era oferecida aos pobres e fornecia formação técnica de nível secundário para dar conta da demanda do mercado de trabalho emergente; de outro, aquela a que tinham acesso os filhos da burguesia industrial e fornecia preparação para a continuidade do ensino superior em universidades de excelência. Essa ação da escola autoritária brasileira da década de 1970 contribuiu para diminuir a demanda por acesso ao ensino superior, restringindo-o aos filhos das elites brasileiras e reprimindo a demanda dos pobres oferecendo-lhes o ensino técnico. A dualidade e seletividade, portanto, são os traços desse modelo de educação que ganharam novos contornos com a ditadura militar e que ainda norteiam a educação no Brasil (PINTO, 2002).

Essa dupla herança, em certa medida, contribuiu na constituição da escola como lugar da autoridade hierarquizada na qual as decisões são tomadas de cima para baixo e na qual as funções estão pré-definidas e devem ser respeitadas hierarquicamente. Criou-se, portanto, uma concepção de organização escolar que pouco ou nada se abre para as vozes dos diferentes sujeitos da educação que dela participam (pais, alunos, professores), o que era de se esperar em um momento histórico no qual os processos e as instituições necessárias à democracia encontravam-se distantes da realidade vivida pela maioria da população.

A abertura democrática da sociedade brasileira ocorrida a partir de 1985 trouxe a esperança de que a democracia, como instituição política central, ganharia realidade prática e teria nas escolas lócus privilegiado para sua prática. $\mathrm{O}$ que temos visto, porém, são muitas contradições que dizem respeito à forma como a educação e a escola são pensadas na realidade, principalmente no que se refere a maior ou menor abertura para a participação dos diferentes sujeitos que compõem a unidade escolar.

Alguns avanços, em termos legais, no que diz respeito a uma maior democracia das unidades escolares, foram feitos a partir do fim do regime militar. O primeiro deles foi a Constituição Federal de 1988 que garantia como um dos princípios norteadores da educação brasileira, no inciso VI do artigo 206, “a gestão democrática do ensino público, na forma lei". Apesar da garantia legal, havia uma lacuna gigantesca entre o que se propunha no referido artigo e a realidade autoritária encontrada nas relações de poder existentes nas diferentes unidades escolares de todo o país. Da mesma forma, não havia detalhamento acerca de quais seriam os procedimentos e princípios básicos para que a gestão democrática pudesse entrar em vigor nas diferentes unidades de ensino.

De certa maneira, a Constituição Federal abria uma importante discussão sobre a questão da autonomia dos sistemas educacionais e mesmo das unidades que compunham tal sistema. Segundo a Constituição, em seu artigo 211, "a União, os Estados, o Distrito Federal e os Municípios organizarão em regime de colaboração seus sistemas de ensino". Tal artigo garante a cada uma das esferas de poder certa autonomia de organização de seus sistemas e de interpretação dos artigos publicados na referida Constituição. Essa autonomia, porém, não resultou, diretamente, em autonomia das unidades escolares que dependem, para a sua plena realização, de elementos tanto de ordem infraestrutural como supraestrutural. A maioria das unidades escolares não possui nenhum poder de decisão, nem goza de autonomia financeira e administrativa, além de ser, em certa medida, refém de mudanças institucionais 
ocorridas em outras instâncias de decisão e que alteram profundamente as práticas dos sujeitos que em suas relações constituem as unidades escolares.

Apesar de ser princípio garantido em lei, a gestão democrática da educação pouco se transformou em ação prática, em realidade capaz de alterar a herança autoritária herdada pela escola brasileira e de criar outras relações entre a escola, lugar e a democracia. Ao contrário, o autoritarismo verificado nas escolas públicas é, em certa medida, resultado de um modelo de democracia que tem sido posto em prática no Brasil e que concebe a democracia como representatividade e não participação. Para além da escola enquanto espaço público, o que temos visto é a escola como extensão do Estado, pensado aqui como patrimonialista, nos termos propostos por Sérgio Buarque de Holanda, no qual, como vimos, os limites entre público e privado não aparecem de forma clara.

Oito anos após a promulgação da Constituição Federal e depois de muita negociação, foi aprovada a Lei de Diretrizes e Bases da Educação, considerada por muitos um avanço, pois consolidou os princípios garantidos na Constituição de 1988. No entanto, a gestão democrática não ganhou grande exploração na referida lei. Havia apenas alguns acréscimos em relação à Constituição Federal de 1988. Segundo a LDB, no inciso VIII do artigo 3, é princípio da educação "a gestão democrática, na forma da lei e da legislação dos sistemas de ensino". Tal item reforça a Constituição Federal ao estabelecer que cabe a cada um dos sistemas de ensino organizar o princípio da gestão democrática da Escola. $\mathrm{O} \S 2$ do artigo 8 reafirma a autonomia dos sistemas de ensino de se organizarem em conformidade com a LDB. Segundo o referido parágrafo do artigo, "os sistemas de ensino terão liberdade de organização nos termos desta lei". Contudo, essa descentralização vista com bons olhos por muitos significou, na prática, uma diversidade de experiências de gestão democrática que dependem, substancialmente, do projeto político dos municípios e estados que são seus proponentes.

Um avanço importante em relação à $\mathrm{CF} 88$ está no artigo 14 da LDB. Tal artigo define os princípios que devem nortear a gestão democrática da educação pública. De um lado, aponta para a necessidade de participação dos profissionais da educação na elaboração da proposta pedagógica da unidade escolar; do outro, afirma a participação da comunidade escolar na organização da escola através da participação em instâncias colegiadas, como os conselhos escolares. Tais conselhos, como veremos adiante, passarão a ter papel decisivo na realização da gestão democrática da escola pública brasileira.

Apesar desses avanços, os debates e práticas em torno do princípio da gestão democrática acabaram ficando em segundo plano frente à realidade de muitos dos municípios e estados brasileiros, mais preocupados em assegurar outros princípios da educação, garantidos em lei, principalmente aqueles que diziam respeito à universalização e obrigatoriedade da educação infantil e do ensino fundamental, e que garantiam maior retorno eleitoral nas urnas.

Podemos, então, afirmar que nos primeiros dez anos de promulgação da LDB ocorreram experiências pontuais de gestão democrática da escola, sendo que muitas delas sofreram rupturas decorrentes da alternância do poder político local. Cada nova administração municipal ou estadual alterava o modelo de gestão democrática e assim o fazia em decorrência dos interesses políticos que possuíam em relação à educação. A gestão democrática passou a depender, portanto, do grau de democracia que existia no cerne da própria administração municipal ou estadual que a propunha. Tal fato nos permite compreender melhor as relações existentes entre educação e poder local em suas diferentes escalas geográficas de reprodução.

\section{Escolas democráticas: princípios e limites}

A partir da década de 1990, como vimos, em decorrência do que havia sido aprovado na Constituição Federal e posteriormente com a LDB de 1996 surgiu uma série de experiências que buscavam fomentar a ideia de gestão democrática da educação brasileira. Entre algumas delas, podemos citar o caso da cidade de Porto Alegre, conhecida mundialmente pela sua gestão democrática durante a década de 1990, posta em prática através da implementação do orçamento participativo e que criou um modelo de gestão democrática da escola pública. O mesmo pode se verificado durante o governo de Luiza Erundina na prefeitura de São Paulo, que primou pela participação popular nas decisões da maioria das 
secretarias municipais, principalmente na educação, durante a gestão de Paulo Freire e Mário Sérgio Cortela.

Mas o que define a gestão democrática de uma escola? Em seu livro Escolas Democráticas, Michael Apple e James Beane apresentam uma série de experiências relatadas por professores e alunos de escolas públicas dos Estados Unidos. Com base nessas experiências, os autores buscam definir alguns elementos que estão presentes na maioria das escolas chamadas democráticas. Segundo os autores, a existência de estruturas e processos democráticos e de currículos que ofereçam experiências democráticas aos jovens são elementos fundamentais para a que democracia, entendida como processo político capaz de possibilitar igualdade de condições e de oportunidades a todos, se realize no interior da escola e contribua na pressão por mudanças em toda a sociedade. Segundo os autores,

As escolas democráticas são marcadas pela participação geral nas questões administrativas e de elaboração de políticas. Comitês, conselhos e outros grupos que tomam decisões no âmbito da escola incluem não apenas os educadores profissionais, mas também os jovens, seus pais e outros membros da comunidade escolar. Nas salas de aula, os jovens e os professores envolvem-se no planejamento cooperativo, chegando a decisões que respondem às preocupações, aspirações e interesses de ambas as partes. Esse tipo de planejamento democrático, tanto no âmbito da escola quanto no da sala de aula, não é uma engenharia da unanimidade para se chegar a decisões predeterminadas que muitas vezes têm criado a ilusão de democracia, mas uma tentativa genuína de respeitar o direito de as pessoas participarem da tomada de decisões que afetam sua vida. (APPLE; BEANE, 2001, p. 20-21).

O trecho acima descreve uma série de estruturas e processos encontrados pelos autores em algumas das escolas democráticas existentes nos Estados Unidos. Podemos perceber que tais estruturas e processos são marcados não apenas por discussões, mas se configuram principalmente como fórum de decisões nos quais as pessoas, nas palavras do autor, podem participar da "tomada de decisões que afetam sua vida". Não é apenas uma democracia de direito, mas, de fato, que se realiza porque as condições para tal foram criadas.
Da mesma forma, as experiências democráticas devem ser incentivadas a partir de conteúdos e situações didáticas que levem os alunos a construir soluções coletivas pautadas no diálogo e no senso comum. Nessa lógica, o sentido de uma educação democrática deve permear e dar significado a todo processo de elaboração pedagógica realizada pelo professor, orientando-o nos caminhos e nas escolhas que deve realizar. Segundo os autores,

Um currículo democrático propõe aos jovens que abandonem o papel de consumidores do saber e assumam o papel ativo de elaboradores de significados. Reconhece que as pessoas adquirem conhecimento tanto pelo estudo de fontes externas quanto pela participação em atividades complexas que requerem a construção de seu próprio conhecimento. (APPLE; BEANE, 2001, p. 29-30).

Para a construção de um currículo que se quer democrático é fundamental a participação de todos aqueles que compõem a comunidade escolar, participação esta que depende da maneira como a unidade escolar está estruturada espaço-temporalmente. Numa experiência democrática, é preciso que a escola, na figura dos seus diferentes sujeitos, crie as condições reais para que todos se sintam à vontade para opinar e percebam que suas opiniões são reconhecidas e podem significar ações. As hierarquias devem ser substituídas pelo diálogo e pela argumentação e as decisões devem ocorrer a partir de votações nas quais deve comparecer a maioria da comunidade escolar.

Como podemos perceber, a escola democrática, pensada nesses termos, é lugar propício para o desenvolvimento da pesquisa, da construção coletiva do conhecimento que se dá, diretamente relacionada com os problemas a serem resolvidos pela comunidade. Não há como pensar a democracia e a cidadania sem pensar numa reestruturação/ressignificação dos espaços públicos com vistas a fomentar a real participação dos sujeitos.

No caso brasileiro, a principal teoria acerca da gestão democrática da escola está alicerçada na obra de Paulo Freire e ganhou força a partir da denominação, por Moacir Gadotti, do termo "escola cidadã". Segundo Gadotti, a escola cidadã educa para e pela cidadania e reconhece, nos diferentes sujeitos que dela participam, cidadãos que têm como principal direito decidir sobre os aspectos políticos, sociais e 
econômicos que afetam direta e indiretamente suas vidas. A escola cidadã está alicerçada em quatro grandes princípios: gestão democrática, comunicação direta, autonomia da escola e avaliação permanente do desempenho. Esses princípios, somados a ações no sentido de propiciar experiências democráticas no interior da escola e fora desta, são elementos fundamentais para que a escola, como lugar de realização da democracia plena, possa se tornar realidade.

A escola cidadã inaugura também outro modelo de escola no que diz respeito a sua organização institucional. Segundo Gadotti (1997, p. 4), a escola cidadã é ao mesmo tempo uma instituição pública, estatal, comunitária e democrática.

Em outros termos, o poder público deve garantir sua manutenção, entregando mais recursos diretamente à escola para que ela, através de sua direção, democraticamente eleita, assessorada por um colegiado representativo da comunidade escolar, elabore, execute e implemente com autonomia seu projeto político-pedagógico.

Em certa medida, a concepção de escola cidadã tem como grande objetivo preencher uma lacuna de participação democrática no Brasil, qual seja, a quase inexistência de instituições e de instâncias públicas e comunitárias para que a experiência democrática se realize de fato. É, portanto, um projeto de escola que se pauta em um projeto de sociedade mais justa, igualitária e democrática, buscando realizar a transgressão da esfera familiar e privada para a construção de uma esfera efetivamente pública, nos termos apontados por Sérgio Buarque de Holanda. É, portanto, elemento fundamental para que possamos compreender que pensar a escola, em seus elementos e em sua organização, é pensar que tipo de sociedade queremos e sobre quais bases tal sociedade será erguida. A escola cidadã como projeto de escola democrática é também projeto de uma sociedade democrática de direito e de fato, que cria as condições necessárias para que os homens e mulheres desta sociedade se realizem enquanto sujeitos históricos e geográficos.

Quando pensamos as experiências democráticas surgidas em alguns sistemas e em algumas unidades de ensino no Brasil é preciso que ampliemos seu significado a partir da leitura das condições po- líticas da sociedade brasileira. Pensar a democracia na escola é pensar a necessidade de construção e de constituição de uma esfera pública no Brasil. O que marca as experiências de gestão democrática da escola é o fato de que foram postas em prática não como estratégias pontuais de governo, mas como princípio básico de administração pública e de participação popular. Nessas experiências, a escola surge como mais uma instância de participação popular que, somada a outras, cria as condições necessárias para a organização de um governo democrático, participativo e popular. A escola surge como instância de organização, fiscalização, negociação, decisão da população frente aos órgãos do governo. Para além de um olhar para si mesmo, a gestão democrática possibilita que a escola, com a participação de seus sujeitos, se transforme naquilo que Moacir Gadotti denominou de "esfera pública de decisão não estatal", fundamental para a transformação das relações de poder no Brasil.

\section{Entre o patrimonialismo e a lógica neoliberal: limites à escola democrática no Brasil}

No entanto, muitos são os desafios para que surjam mais experiências de escolas democráticas no Brasil. No momento atual, vivemos, ao mesmo tempo, os impactos do Estado patrimonialista decorrente, como vimos, de nosso processo de colonização e da lógica neoliberal que buscam entregar à iniciativa privada aquilo que ainda nem se constitui como público no país. Tais impactos são mais intensos uma vez que a dinâmica histórica do desenvolvimento de nossa sociedade não permitiu o aparecimento de uma sociedade civil autônoma, consciente dos seus direitos e capaz de fiscalizar o Estado a ponto de torná-lo transparente. Com isso, inúmeros obstáculos surgem para a efetiva democratização da sociedade brasileira.

Marilena Chauí (2006) aponta, pelo menos dois grandes obstáculos que impedem a realização da democracia plena no Brasil: o "Autoritarismo Social" e a "Despolitização". Como autoritarismo social a autora entende todo o processo que leva à naturalização das contradições sociais que marcam o país, principalmente no que diz respeito à gritante desigualdade social, base da desigualdade de acesso 
e garantia de direitos constitucionalmente assegurados. Esse autoritarismo se afirma a partir de uma estrutura política que tem como principal objetivo afastar a grande maioria da população das condições de realização de seus direitos, ou seja, da participação efetiva nas decisões que dizem respeito à vida pública e ao bem comum. Nesse sentido, o que temos é o monopólio do poder e do saber político que se sustenta com base nesse processo de naturalização das contradições sociais e da justificativa, por meio do discurso sofista, das hierarquias de saber e poder que se estruturam histórica e geograficamente. É, portanto, a vitória, pelo menos momentaneamente, da personalização do poder, da tutela e do favor político, do par dual carência e privilégio, que marca o cenário político brasileiro, extremamente distante do que vem a ser uma experiência democrática.

De outro lado, a crescente despolitização que ocorre não apenas no Brasil, mas se configura como fenômeno mundial e tem relação direta com o processo de reprodução ampliada do modo de produção capitalista, se apresenta na prática como encolhimento do espaço público a partir da implantação da chamada concepção neoliberal do Estado (HARVEY, 2008). Tal concepção, nascida como tentativa de solução para a crise mundial de acumulação capitalista da década de 1970, atingiu o Brasil e a América Latina a partir da década de 1990 com a execução das propostas definidas exogenamente no Consenso de Washington, de 1989. No caso do Brasil, esse processo aprofundou ainda mais as contradições sociais existentes no sentido em que contribuiu para desmontar uma esfera pública que, em certa medida, havia surgido há muito pouco ou que de fato nunca existiu, como apontou Sérgio Buarque de Holanda.

Esses obstáculos têm contribuído para que as experiências das escolas democráticas no Brasil se restrinjam a alguns municípios, ocorrendo de forma bastante precária. Além disso, predomina uma visão do espaço escolar como restrito aos seus administradores, como continuidade do espaço privado. São comuns práticas religiosas no interior da escola, que vão da colocação de um crucifixo em algum ambiente até a realização de missas e cultos, alguns inclusive com a desculpa de buscar resolver os problemas de indisciplina nas escolas. Essa confusão entre público e privado, própria do Estado patrimonialista, se materializa de forma bastante clara no espaço escolar e traz profundas consequências na tentativa de democratização efetiva da escola no Brasil.

Além disso, o avanço das políticas neoliberais em diversas áreas no país tem produzido efeitos perversos na organização da escola e no processo educativo. Um exemplo disso está na rede estadual de São Paulo, que mantém a estrutura autoritária de organização escolar. Nessa organização, a discussão é substituída pela hierarquia. Há pouca ou nenhuma transparência financeira e administrativa, o que levanta uma série de suspeitas sobre desvios de verba e de ações que indicam corrupção. Da mesma maneira, as reformas neoliberais postas em prática nessa rede têm contribuído para o aumento excessivo da burocracia e do controle sobre o trabalho docente, outro elemento impeditivo da gestão democrática visto que impossibilita a existência de tempo para discussões e para a construção de soluções coletivas para os problemas da unidade escolar.

O que temos visto no caso do estado de São Paulo é a repetição de um modelo centralizado de administração no qual as mudanças vêm sempre de cima, com pouca ou nenhuma participação dos sujeitos da educação e que resultam em ações desastrosas do ponto de vista pedagógico. Além disso, sustentam-se a partir de um discurso técnico racional que busca reduzir a prática educativa a esta dimensão. Podemos citar, como exemplo, a implementação da progressão continuada feita sem a devida discussão com pais, alunos e professores e que se pautou mais em interesses políticos (acordos com órgãos internacionais como o FMI e o BIRD) do que em aspectos pedagógicos, bem como a adoção de uma nova proposta curricular ocorrida em 2008 e que discutiremos adiante. Tais mudanças, vindas sempre de cima, criam uma sensação nos sujeitos envolvidos de que tudo é alterável sem prévio aviso e que os interesses políticos momentâneos estão acima de qualquer projeto de educação democrático, popular e participativo.

A nova proposta curricular do estado de São Paulo é a marca central das reformas neoliberais postas em prática no Estado. Sem a participação de professores, alunos e pais, a proposta foi elaborada por técnicos da Secretaria Estadual de Educação, com apoio de alguns professores universitários. Nela, há um modelo único de como deve ser o ensino e a aprendizagem de todos os conteúdos curri- 
culares a ser trabalhados na rede estadual. Além de apostilas para os alunos, a nova proposta curricular distribui apostilas para professores e gestores com explicações de como deve ser conduzido o processo educativo. Não há espaço para a criação nem liberdade dos professores e alunos. Em toda e qualquer escola de São Paulo, independentemente de seu contexto e situação, os conteúdos, as metodologias e as avaliações a serem aplicadas devem ser as mesmas. Para os gurus da proposta, isso facilitaria o processo, tornando-o mais "eficaz".

A busca pela "eficiência" da escola é uma das características principais do neoliberalismo na educação. Por eficiência deve-se entender a economia de material e tempo na produção de uma determinada mercadoria. No caso das escolas sob a lógica neoliberal, tais mercadorias são números e mais números que, para os especialistas competentes, comprovariam o avanço do aprendizado dos alunos e, consequentemente, da eficácia da escola e do sistema de ensino. Para completar o sistema, basta atrelar o salário dos professores a uma suposta produtividade, ou seja, ao número de alunos aprovados por turma. Quanto mais produtivo o professor, maior será a produtividade da escola e do sistema e, portanto, sua eficácia. A política do bônus por mérito aos professores é "a cereja no bolo" dessa reforma neoliberal da educação.

Todo esse processo está envolto em uma profunda racionalidade técnica. Segundo Contreras (2002, p. 90),

A ideia básica do modelo de racionalidade técnica é que a prática profissional consiste na solução instrumental de problemas mediante a aplicação de um conhecimento teórico e técnico, previamente disponível, que procede de pesquisa científica. É instrumental porque supõe a aplicação de técnicas e procedimentos que se justificam por sua capacidade para conseguir os efeitos ou resultados desejados.

Nessa racionalidade, apenas a dimensão técnica da prática educativa é reconhecida. Problemas vinculados às diferentes dimensões da educação (política, ética, estética) são postos de lado, vistos como indiferentes e não científicos, valorizando-se assim um conhecimento instrumental que quer a tudo controlar e submeter. Tal racionalidade concebe professores, alunos e escola como equivalentes, descolados de um contexto e uma situação, e por isto alvo de políticas centralizadoras, que requerem investimentos menores. A imagem da escola nessa racionalidade técnica é semelhante à da fábrica e sua linha de produção. No entanto, em vez de parafusos, se produz alunos em massa. Ou melhor, alunos como massa.

Nesse sentido, as reformas neoliberais avançam sobre a organização da escola e do processo educativo, trazendo novas práticas e discursos que buscam ser naturalizados a partir de uma lógica da aceitação e submissão dos diferentes sujeitos da escola. O que de fato pretendem os gurus das reformas neoliberais (na maioria dos casos, economistas neoclássicos, com pós-graduação em importantes departamentos de economia do Brasil e do mundo) é fazer com que a lógica perversa do capital, historicamente constituída, seja concebida como natural e irreversível, como única alternativa possível para o desenvolvimento social. Em certa medida, tal objetivo tem sido alcançado quando encontramos, nas escolas em que realizamos nosso trabalho de campo, professores e diretores apáticos frente a todos estes processos, incapazes de questionar e refletir acerca das práticas burocráticas, de controle e regulamentação, que as reformas neoliberais têm posto em prática nas diferentes unidades escolares do país.

Em 2007, o governo paulista lançou um plano de 10 metas para a educação pública do estado a serem alcançadas até o ano de 2010. O que chama a atenção é que em nenhuma das metas aparece a questão da gestão democrática. Ao contrário, entre as medidas propostas para alcançar as metas há uma que aponta o fortalecimento do papel do diretor da escola na liderança do processo de implantação do modelo de gestão, ampliando assim a centralização das decisões. Vale ressaltar que tal modelo de gestão está sendo discutido no âmbito da Secretaria Estadual de Educação, sem o envolvimento das unidades escolares e, portanto, da comunidade escolar.

O que podemos perceber é um claro processo de centralização das decisões relacionadas à educação que pressupõe decisões tomadas e implementadas de cima para baixo. Na concepção da Secretaria Estadual de Educação, aparece de forma implícita que o fortalecimento da figura do diretor é fundamental neste processo para que as resistências a tais mudanças sejam cada vez menores. O diretor se 
torna, portanto, soldado da linha de frente que tem como principal objetivo defender as mudanças e implementar um modelo de gestão construído sem a participação da comunidade escolar e que, em suma, pouco tem de democrático em sua concepção.

É interessante notar que ao mesmo tempo que as decisões acerca da escola centralizam-se cada vez mais no poder executivo e excluem a comunidade escolar, a mesma é convocada pelo Poder Executivo a participar de determinadas ações na escola que deveriam ser obrigações do poder estadual. Há alguns anos, o governo paulista lançou o projeto Trato na Escola. Nesse projeto, o governo conclama a comunidade de cada escola a colaborar, inclusive financeiramente, para a reforma da infraestrutura da mesma. Cada escola recebeu o equivalente a $\mathrm{R} \$$ 7.000,00 para fazer as adequações necessárias - um valor muito baixo para uma real adequação infraestrutural da escola. Vale ressaltar que as alterações previstas já estavam definidas pela própria Secretaria de Educação, sendo que a comunidade escolar participaria apenas de suas execuções. O que temos, portanto, é uma falsa ideia de gestão democrática da escola cujo objetivo é acobertar um processo de implementação de uma gestão neoliberal do Estado que tem como sua principal marca a diminuição dos gastos públicos. Entre as consequências dessa gestão neoliberal podemos citar a dependência financeira cada vez maior das unidades escolares, não apenas em São Paulo, mas em diferentes estados e municípios da federação, dos recursos arrecadados pelas Associações de Pais e Mestres (APMs), muitas vezes de forma ilegal por meio da cobrança obrigatória de taxas de matrícula, que ferem o direito constitucionalmente garantido da gratuidade da educação básica.

Portanto, os desafios da construção de uma escola efetivamente democrática no Brasil passam pelo enfrentamento tanto das práticas patrimonialistas da gestão da coisa pública quanto pelo avanço atual das políticas neoliberais que querem transformar em privilégio aquilo que constitucionalmente se configura como um direito. Vale ressaltar que estamos diante de modelos opostos de gestão da escola os quais remetem diretamente a modelos diferentes de organização da própria sociedade. De um lado, o modelo patrimonialista e neoliberal, baseado na diminuição da ação estatal das ações que obrigato- riamente lhe cabem e a entrega das mesmas, quando convém, aos interesses do mercado e dos agentes privados, o que resulta numa privatização ampliada do espaço público e num processo de despolitização. Do outro, um modelo de gestão democrática, popular e participativa, que tem como principal elemento fundador a criação de instâncias públicas de participação efetiva da população e de exercício pleno da cidadania. Tais modelos, em diferentes escalas, permeiam as escolas públicas brasileiras e revelam as contradições existentes numa sociedade que mesmo antes de ser pública vai sendo privatizada.

\section{Considerações finais: reconstruir a escola para construir a democracia}

Como vimos, pensar as relações entre escola pública e democracia no Brasil passa necessariamente pela compreensão dos interesses políticos e do modelo de democracia que se quer implementar. As relações e os conflitos que resultam dessa relação, antes de serem negados, devem se tornar objetos de discussão e construção coletiva do diálogo e do debate. Um dos instrumentos capazes de fomentar esse debate e, consequentemente, uma maior participação da comunidade nas decisões que envolvem a escola é o Projeto Político-Pedagógico desenvolvido no âmbito da unidade escolar e que, em certa medida, revela interesses e intenções que, num primeiro momento, ficam ocultas nas relações socioespaciais que ali ocorrem.

Como vimos, a gestão democrática tem sido colocada em prática no Brasil em diferentes sistemas de ensino, a partir de uma visão neoliberal de educação que entende autonomia como "desresponsabilização" do poder público sobre o direito à educação. Essa "desresponsabilização" tem sido verificada a partir da ocorrência de ações cada vez mais privatistas da educação. Tais ações têm como principal objetivo reduzir o orçamento das unidades escolares e da educação em geral, que passa a ser entendida como custo e não como direito inalienável de todo cidadão. Para além de uma visão pessimista da questão, faz-se necessário apontar caminhos e estratégias que possam se contrapor a esse modelo neoliberal de educação. Para tanto, acreditamos que a construção coletiva de uma escola democrática 
inclui uma serie de ações que gostaríamos de analisar aqui.

A primeira diz respeito ao reconhecimento do poder e significado do Projeto Político-Pedagógico (PPP) (VASCONCELLOS, 2007) da Unidade Escolar que, se levado às últimas consequências, pode representar uma transformação real e qualitativa das relações socioespaciais que configuram as práticas pedagógicas e políticas que ocorrem na escola.

No que consiste o Projeto Político-Pedagógico? Basicamente, o PPP é resultado da forma como a comunidade escolar, a partir de seus diferentes sujeitos, compreende e se relaciona com o lugar e com o mundo a partir da educação. No PPP estão explícitos os alicerces que sustentam as práticas pedagógicas e socioespaciais daquela comunidade escolar. Define as relações dos sujeitos e as concepções que as permeiam. Por se tratar de uma construção coletiva, não pode ser pensada sem a ocorrência do diálogo e do conflito. Em certa medida, o PPP é o resultado das negociações que atravessam os diversos interesses que emergem da relação entre escola, sujeito e lugar. Segundo Santos (1998, p. 96-97),

Cada lugar tem, pois, variáveis internas e externas. A organização da vida em qualquer parte do território depende da imbricação desses fatores. As variáveis externas se internalizam, incorporando-se a escala local. Até o momento no qual impactam sobre o lugar são externas, mas o processo de espacialização é, também, um processo de internalização.

Por isso, o PPP traz para o interior da escola a problemática do lugar em que aquela comunidade escolar está inserida e que, muitas vezes, pelo medo do entorno, por práticas sucessivas de fechamento ou por receio daquilo que o lugar pode revelar, não é levado em consideração na definição de práticas pedagógicas. Em vez de negar o lugar em suas múltiplas implicações, o PPP reafirma a ligação intrínseca entre lugar e educação, encarando tal ligação como elemento fundamental de inserção da escola e dos seus sujeitos no mundo. É a partir do reconhecimento do lugar, de suas implicações, das práticas socioespaciais que ele sustenta e pelas quais é sustentado que a escola em suas reais condições de existência pode definir caminhos, visões, projetos que podem se articular ou se contrapor aos modelos e estratégias advindos de cima para baixo e que re- metem a outras lógicas, a outros interesses que não aqueles vinculados à ideia de democracia e de bem público.

Dessa forma, quando pensamos na importância da construção coletiva do PPP como elemento fundamental na construção da autonomia e da gestão democrática da unidade escolar, buscamos resgatar aquilo que há de geográfico nesta questão, qual seja, o fato de que o PPP surge também de um diálogo crítico e criativo entre escola e lugar. O PPP situa a escola e seus sujeitos, permitindo aos mesmos o olhar sobre o mundo a partir de um lugar, que não é, porém, o único. A reconstrução constante do Projeto Político-Pedagógico como prática presente numa escola democrática possibilita aos sujeitos repensar constantemente os lugares e as situações de onde falam e onde se relacionam com o mundo. É também a oportunidade de realização da cidadania, no sentido em que envolve a participação e a construção crítica e criativa de um projeto de ação que visa assegurar direitos alienáveis do cidadão. Como lócus da construção coletiva desse projeto, a escola, em certa medida, passa por um processo de ressignificação, no qual, à sua função educativa, vem somar uma série de outras funções que dizem respeito ao exercício da cidadania e a realização da democracia.

Outro ponto fundamental é o fortalecimento das diferentes instâncias de participação da comunidade escolar nos processos que envolvem a organização da prática educativa. Retomando aquilo que está posto no artigo 14 da LDB, evidente está que uma dessas principais instâncias é o conselho de escola, órgão máximo no qual as decisões que afetam toda a comunidade escolar devem ser tomadas de forma coletiva e participativa. É preciso resgatar a importância desse órgão e torná-lo, de fato, presente em diferentes momentos da organização escolar. Os professores, diretores e coordenadores pedagógicos precisam, urgentemente, compreender o potencial educativo desse órgão, uma vez que é também por meio dele que os pais, alunos e funcionários podem se apropriar da escola enquanto espaço público e com isto se tornar de fato corresponsáveis por aquilo que ali acontece.

É interessante notar que ao mesmo tempo que professores e diretores reclamam da não participação dos pais no acompanhamento da vida escolar dos filhos também não criam estratégias para que os 
mesmos participem deste momento importante da organização da vida escolar. Na maioria das vezes, os pais não são chamados para discutir como deve ser a escola, mas apenas para escutar ou aprovar medidas que foram tomadas sem sua real participação. Ou, em uma prática ainda mais perversa, como vimos, são convocados em momentos nos quais a escola necessita de dinheiro (seja para vender uma rifa ou pizza, seja para contribuir diretamente no trabalho da escola). Assim, reafirmam-se as políticas neoliberais de educação que sobretaxam os pais e "desresponsabilizam" o Estado em relação aos investimentos obrigatórios.

O mesmo ocorre em relação aos estudantes. Em todos os currículos, nas páginas de apresentação dos livros didáticos, nos planos de trabalho docente é comum encontrarmos que um dos objetivos da educação é a formação de um aluno crítico. Mas o que de fato significa isso? Como se constrói essa tal aclamada criticidade? É possível formar um aluno crítico na teoria? Um olhar mais atento para as práticas que ocorrem no interior das escolas nos faz perceber que existe um descompasso entre aquilo que está posto no discurso e o que se realiza na prática. Queremos um aluno parcialmente crítico. O mesmo pode até tecer críticas à invasão do Iraque, à corrupção no governo federal ou até mesmo na prefeitura, mas se começar a se interessar pela sua comunidade e questionar como o dinheiro da escola é gasto e por que nenhum aluno é consultado sobre aquilo que acontece esta criticidade se transforma em incômodo e pode, inclusive, resultar em punição. Portanto, é possível perceber que o discurso da criticidade pode ocultar práticas autoritárias que visam excluir os alunos das decisões da escola e com isso contribuem para que os mesmos não desenvolvam a autonomia e reflexão necessárias à prática da cidadania.

Para reverter essa situação, faz-se necessário que os alunos sejam instigados a participar ativa e criticamente da organização da escola. Para isso, devem se organizar por meio de grêmios estudantis e reconhecer os direitos que possuem e que estão previstos tanto na LDB como no Estatuto da Criança e do Adolescente (ECA). O papel dos alunos é fundamental para a democratização da escola, uma vez que são eles os principais sujeitos da educação e o sentido de todo o trabalho educativo. Além disso, ao se apropriar da escola como lugar público e coletivo, os alunos mudam sua relação com aquele espaço e podem possibilitar outras práticas educativas que rompam com a violência e a indisciplina, marcas características das escolas públicas contemporâneas. É na escola que os alunos constroem sua primeira experiência política e se afirmam ou não como cidadãos atuantes, responsáveis e críticos. E por isso a importância de fomentar tais ações.

Por último, é fundamental reconhecer que a construção de uma escola democrática não pode estar dissociada de práticas educativas democráticas. Ao pensar e construir o currículo, os professores das diferentes disciplinas devem levar isto em consideração. De nada adianta uma escola com grêmio e conselho escolar atuantes se resistem, em sala de aula, práticas autoritárias. O conhecimento deve ser posto a serviço da construção de ações democráticas e para tanto é preciso também ser construído democraticamente. Isso significa dizer que ao pensar o seu curso, a sua disciplina, o professor necessita levar em consideração a realidade da comunidade escolar, os conhecimentos prévios dos alunos, bem como o sentido e a função social dos objetivos e conteúdos que pretende trabalhar. Sem clareza em torno disso e sobre as inter-relações que formam a unidade escolar, corre-se o risco da construção democrática da escola ser apenas mais um discurso em meio a tantos outros que permeiam a educação pública contemporânea.

A escola pública brasileira, ao revelar as contradições de uma estrutura política baseada nos privilégios e não nos direitos, pode se tornar lócus da reconstrução da cidadania, permitindo a cada um dos sujeitos modificar as relações que estabelece com o Estado. Para além de espaço estatal, a escola reapropriada torna-se espaço público, porque é resultado das negociações, dos diálogos construídos entre os diferentes sujeitos que dela participam. Para além do lugar do paternalismo, dos programas assistenciais, torna-se lugar de realização dos direitos (à cidade, à educação, à cultura) e a possibilidade de se identificar, na fala dos seus pares e na ação coletiva em prol do bem comum, como cidadão de verdade. 


\section{Referências}

APPLE, M.; BEANE, J. (orgs.) Escolas Democráticas. $2^{\circ}$ edição. São Paulo, Cortez, 2001.

BRASIL. Constituição da República Federativa do Brasil. Brasília: Governo Federal, 1988.

BRASIL. Lei de Diretrizes e Bases da Educação Nacional. Brasília: MEC, 1996.

CHAUÍ, MARILENA. "Democratização e transparência: a tarefa do PT contra a despolitização e pela construção de uma ética pública" IN GUIMARÃES, J. Leituras da Crise. São Paulo, 2006.

CONTRERAS, J. Autonomia de professores. São Paulo: Cortez, 2002.

FAORO, R. Os donos do poder. $3^{\circ}$ edição. Rio de Janeiro: Globo, 2001.

GADOTTI, MOACIR. Escola Cidadã: Educação para e pela cidadania. São Paulo: IPF, 2007.

HARVEY, D. O Neoliberalismo. São Paulo: Loyola, 2008.

HOLANDA. S. B. Raízes do Brasil. $26^{\circ}$ edição. São Paulo: Cia das Letras, 2001.

PINTO, J. M. "O Ensino Médio" IN OLIVEIRA, R. P.; ADRIÃO, T. (Orgs.) Organização do Ensino no Brasil. São Paulo: Zamã, 2002.

SANTOS, M. Metamorfose do Espaço Habitado. São Paulo: Hucitec, 1998.

SÃO PAUlO. Proposta Curricular do Estado de São Paulo - Geografia. São Paulo: SEE, 2008.

TIRAMONTI, Guilhermina. "La escuela em la encrucijada del cambio epocal". In Educação e Sociedade, Campinas, vol.26, n. 92, p.889-910, Especial - Out. 2005.

VASCONCELLOS, C. dos S. Planejamento: projeto de ensino aprendizagem e projeto político pedagógico. $17^{\circ}$ edição. São Paulo: Libertad, 2007.

Data de Submissão: junho de 2012

Data de Aprovação: dezembro de 2012. 
